\title{
Infrared and Raman Spectroscopic Study of Carbon-Cobalt Composites
}

\author{
André Tembre, Jacques Hénocque, and Martial Clin \\ Laboratoire de Physique de la Matière Condensée, Université de Picardie Jules Verne, 33 Rue Saint Leu, \\ 80039 Amiens Cédex 1, France \\ Correspondence should be addressed to Martial Clin, martial.clin@u-picardie.fr
}

Received 20 May 2011; Revised 22 July 2011; Accepted 13 August 2011

Academic Editor: Ahmed Aamouche

Copyright ( 92011 André Tembre et al. This is an open access article distributed under the Creative Commons Attribution License, which permits unrestricted use, distribution, and reproduction in any medium, provided the original work is properly cited.

Analysis of carbon-cobalt thin films using infrared spectroscopy has shown existence of carbon-cobalt stretching mode and great porosity. The Raman spectroscopy and high-resolution transmission electron microscopy have been used in order to investigate the microstructure of the films. These films exhibit complex Raman spectra suggesting the presence of amorphous and crystallized phases. The different fractions of phases and the correlation between the atomic bond structures and the Raman features depend on the cobalt content.

\section{Introduction}

In the last years, nanocrystalline magnetic materials made of metallic nanoclusters dispersed in an amorphous matrix have attracted considerable interest owing to their magnetic properties and promising applications as memory units for high-density storage and fundamental research $[1,2]$. Hayashi et al. [3] have reported the fabrication and characterization of magnetic thin films of h.c.p cobalt nanocrystals of around $8 \mathrm{~nm}$ size encapsulated in graphite-like carbon cages. Due to their ferromagnetic nature, the cobalt grains have great potential for ultra-high-density magnetic recording media.

The incorporation in the carbon network of various metallic atoms, like Ti, $\mathrm{Zr}$, Ta, $\mathrm{Cr}, \mathrm{Mo}, \mathrm{W}, \mathrm{Fe}, \mathrm{Co}$, and $\mathrm{Ni}$, is a good alternative to improve the tribological [4-7], electric [8-10], and magnetic [11-15] properties of carbon films for various applications as solid lubricant films, microelectrodes, or magnetic films. It has been reported that insertion of metallic atoms in amorphous carbon matrix changes the fraction of $\mathrm{Csp}^{3}$-coordinated carbon sites [16]

Various techniques have been used to fabricate metallic nanoclusters dispersed in an amorphous matrix; we can mention filtered cathodic vacuum arc $[17,18]$, pulsed laser deposition [19], cosputtering [10, 20], and dual beam evaporation system [5]. Among these different methods, cathodic arc deposition is widely used [21,22]; this technique is characterized by high degree of ionization and great ion kinetic energy and deposition rate. Cathodic arc processes produce unwanted macroparticles in the $\mathrm{mm}$ range which are removed from the plasma by a magnetic filter; on the contrary, anodic arc do not suffer from macroparticles contamination, which was the main motivation of using this deposition technique in the present study.

Recently, it has been reported that incorporation of iodine in amorphous carbon $[23,24]$ and boron in diamond [25] leads to a metal-insulator transition at low temperature. Cobalt-doped carbon thin films at $0.3 \%$ cobalt content, deposited by a pulsed anodic electric arc technique, have shown anomalous behaviour on electric and magnetic susceptibility measurements and evidence of metal-insulator transition around $60 \mathrm{~K}$ [26]. This work aims at obtaining more information about the correlation between microstructure and features of infrared and Raman spectra of these carbon-cobalt thin films.

\section{Experimental Details}

The carbon-cobalt films were deposited by pulsed anodic electric arc system, using graphite rod electrodes of $6 \mathrm{~mm}$ diameter. The anode was made of pure graphite rod stuffed with $\mathrm{C} / \mathrm{Co}$ powder in a hole of $3 \mathrm{~mm}$ diameter in the center 


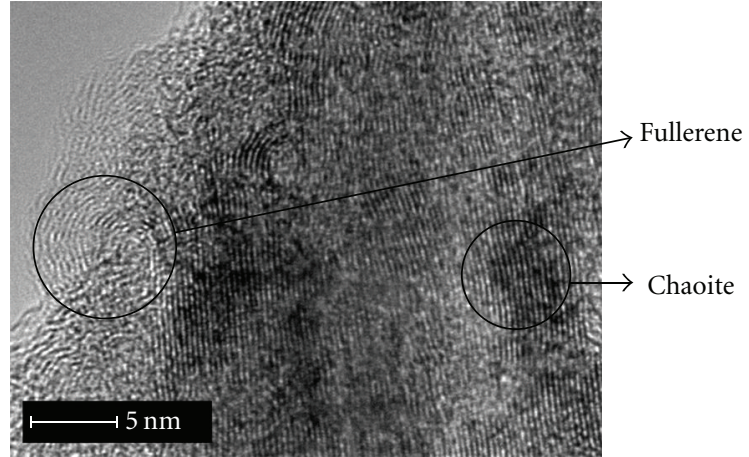

FIGURE 1: HRTEM image obtained for 0.3\%-cobalt-doped carbon thin film. Regions with curved fringes of fullerene like graphitic layers and chaoite structure can be seen.

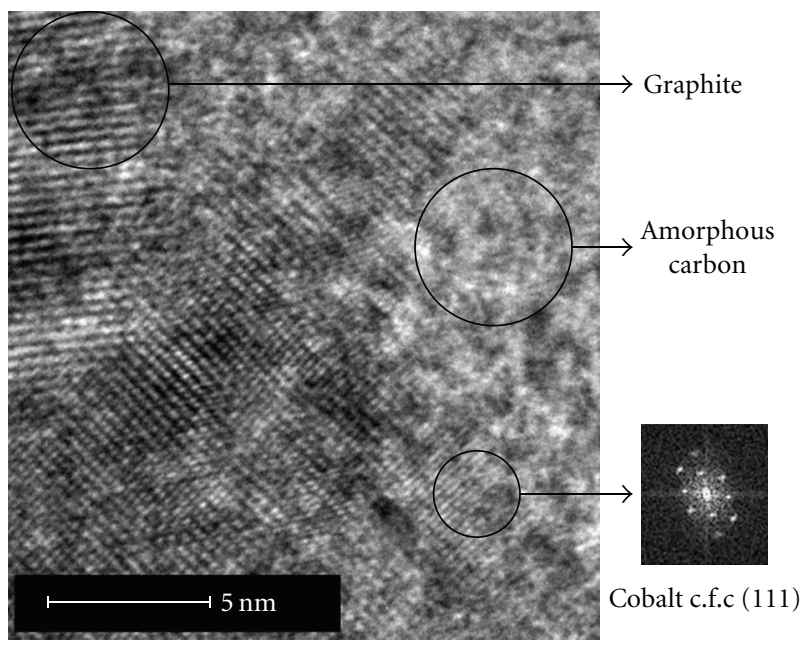

FIGURE 2: HRTEM image obtained for 0.3\%-cobalt-doped carbon thin film. Regions with graphitic and amorphous carbon are shown. Crystallized cobalt aggregate of about $5 \mathrm{~nm}$ size can be seen.

of the rod. The cathode was made of pure graphite rod. Both purities of graphite and cobalt powder were $99.9 \%$. The anodic arc is triggered when cathode and anode touch each other. The arc current was $70 \mathrm{~A}$, and DC discharge voltage was $40 \mathrm{~V}$ with an arc duration of $1 \mathrm{~s}$ and pulse repetition rate of $5 \mathrm{~Hz}$. A bias voltage of $\mathrm{DC}-400 \mathrm{~V}$ was applied to the substrate holder. The base pressure of the deposition chamber was $0.1 \mathrm{~Pa}$. The content of cobalt in carbon films was determined by atomic absorption using a Perkin Elmer Analyst 300 apparatus. The cobalt content is monitored by the percentage cobalt in the $\mathrm{C} / \mathrm{Co}$ powder used to made anode. The thickness of the films was about $400 \mathrm{~nm}$.

The nanostructure of the films were observed by high resolution transmission electron microscopy (HRTEM) equipped with a microanalysis probe at accelerating voltage of $200 \mathrm{kV}$.

Fourier transform infrared measurements were performed using a Nicolet 510 spectrometer in the 400$4000 \mathrm{~cm}^{-1}$ range. The Raman spectra were recorded by a Jobin Yvon T64000 triple monochromator Raman spectrometer. An argon ion laser with a wavelength of $514.5 \mathrm{~nm}$ served

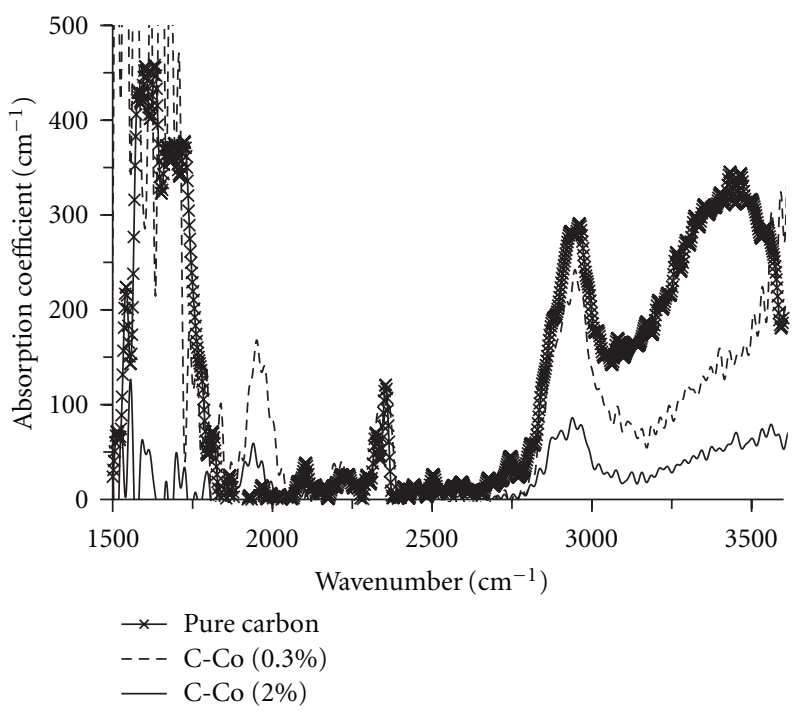

FIGURE 3: Infrared absorption spectra for different Co contents of C-Co films deposited by anodic arc plasma.

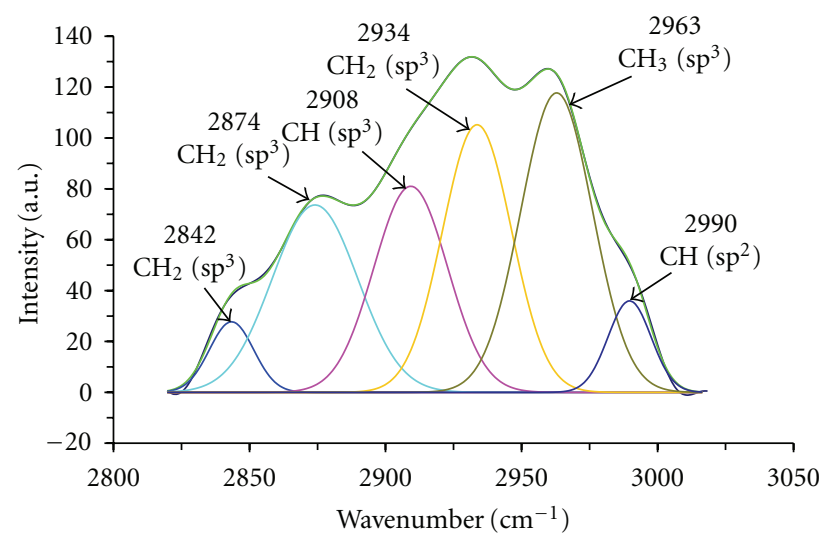

FIGURE 4: Deconvoluted infrared spectrum of pure carbon film in the region of the $\mathrm{sp}^{2}$ - and $\mathrm{sp}^{3}$-hybridised bonds.

as the excitation source. The laser power was limited to $50 \mathrm{~mW}$ in order to prevent any material heating and damage. By using an Olympus BX40 microscope with a 50x objective lens, the explored area was limited to $3 \mu \mathrm{m}^{2}$.

\section{Results and Discussion}

The microstructure by HRTEM of doped and nondoped cobalt carbon films exhibits amorphous and crystallized zones which correspond to different phases of carbon. The presence of nanocrystallites of cobalt in doped cobalt samples is clearly evidenced by HRTEM and electron diffraction studies, and confirmed by microanalysis probe data. Figures 1 and 2 present a HRTEM images of sample for $0.3 \%$ cobalt content. These images show a mixture of amorphous and crystallized phases of carbon. Structures corresponding to graphite, chaoite, and fullerene were identified. The presence of cobalt was detected by microanalysis probe on regions well crystallized of an average size of approximately 


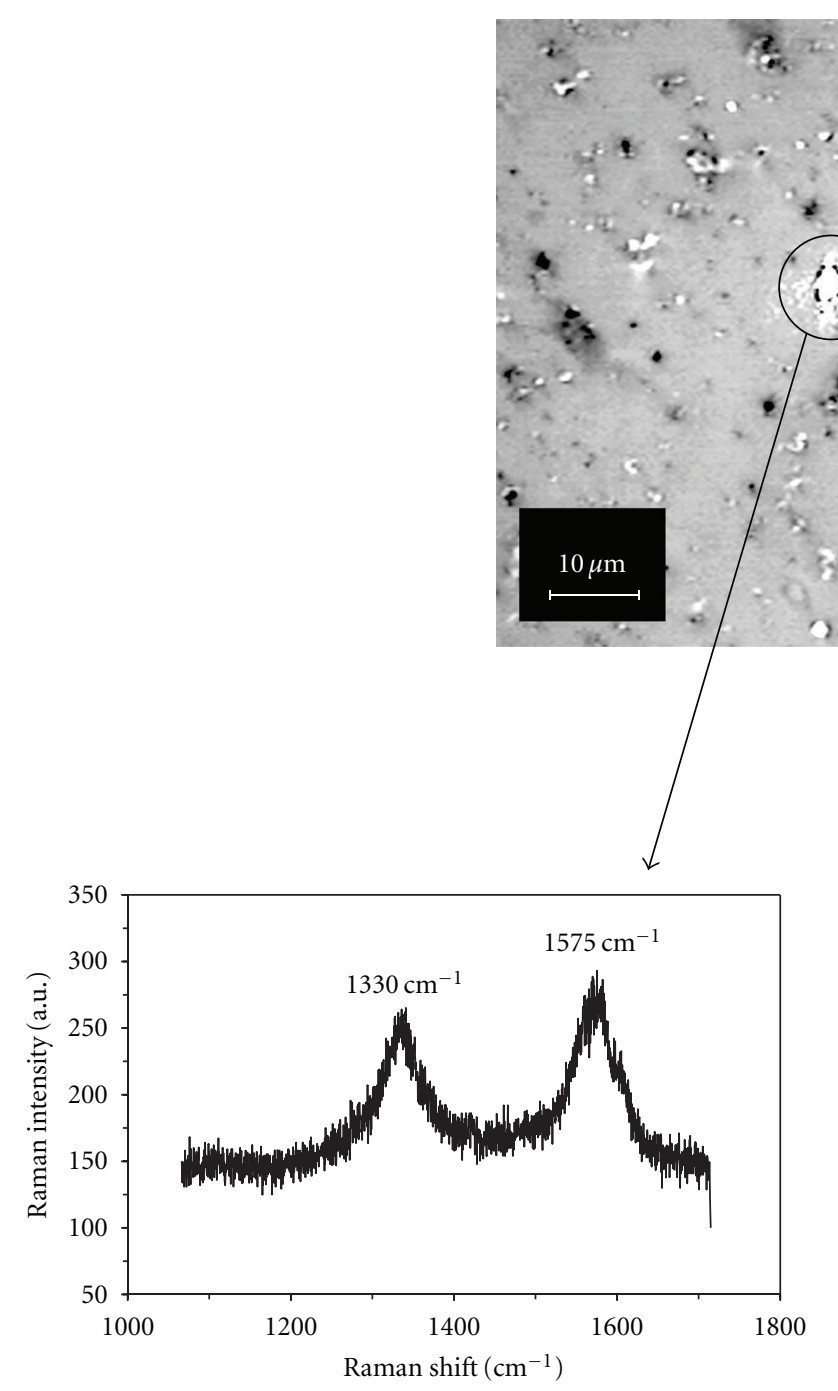

(a)

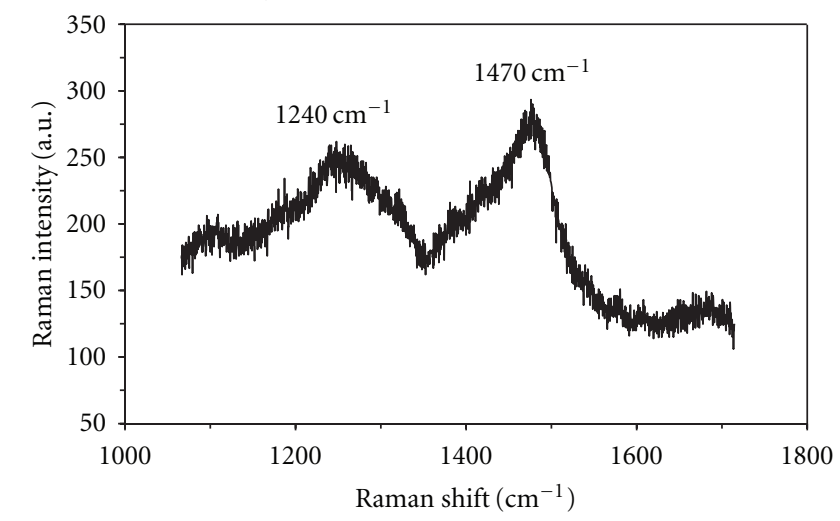

(b)

FIGURE 5: Raman spectra of pure carbon films showing the two types of D-G (sub) bands.

$5 \mathrm{~nm}$ corresponding to a fringe spacing of $0.21 \mathrm{~nm}$ close to that of the interlayer separation in c.f.c Co (111).

Before starting the discussion on the Raman results, let us examine the features of the infrared spectra in the range $1500-3600 \mathrm{~cm}^{-1}$ with a resolution of $2 \mathrm{~cm}^{-1}$. We present on Figure 3 the infrared spectra for, respectively, $0 \%, 0.3 \%$, and $2 \%$ cobalt contents. The strong fluctuation of the signal observed up to $1700 \mathrm{~cm}^{-1}$ can be assigned to the electric conductivity of the films. The peak around $1950 \mathrm{~cm}^{-1}$ which does not appear in pure carbon film is attributed to the linear mode of the $\mathrm{CoC}_{3}$ configuration [27]. A quite surprising behavior is observed for $0.3 \%$ cobalt sample compared to that of $2 \%$ cobalt sample. Indeed, the intensity of the $1950 \mathrm{~cm}^{-1}$ band is surprisingly lower for the $2 \%$ cobalt sample compared to $0.3 \%$ cobalt sample. This result suggests that cobalt in this material tends to segregate into clusters when the cobalt content increases. The band around $2350 \mathrm{~cm}^{-1}$ can be attributed to the $\mathrm{O}-\mathrm{C}-\mathrm{O}$ antisymmetric stretching vibration of $\mathrm{CO}_{2}$ in air. Above $2500 \mathrm{~cm}^{-1}$, in the region between 2800 and $3100 \mathrm{~cm}^{-1}$, the wide broad band centered at approximately $2900 \mathrm{~cm}^{-1}$ is due to the $\mathrm{C}-\mathrm{H}$ vibrational mode and its different configurations [28]. We have performed a computed deconvolution of the experimental infrared spectra in order to assign the different $\mathrm{C}-\mathrm{H}$ bondings which are reported in Figure 4 . The fact that the intensity of this broad band decreases proportionally with increasing cobalt content suggests that the presence of cobalt in the carbon matrix inhibits the $\mathrm{sp}^{3}$-hybridized C$\mathrm{H}$ bonds in accordance with the results previously reported for insertion of metallic atoms in an amorphous matrix [29]. The wide band observed at $3400 \mathrm{~cm}^{-1}$ indicates a contamination of the samples by oxygen or water (which corresponds to the $\mathrm{O}-\mathrm{H}$ bond-stretching mode).

Micro-Raman spectroscopy is one of the most informative methods for investigation of the microstructure of carbon. It is well known that natural diamond has a single Raman peak at $1332 \mathrm{~cm}^{-1}$, whereas crystalline graphite has a Raman peak referred to as the $G$ peak around $1580 \mathrm{~cm}^{-1}$ 


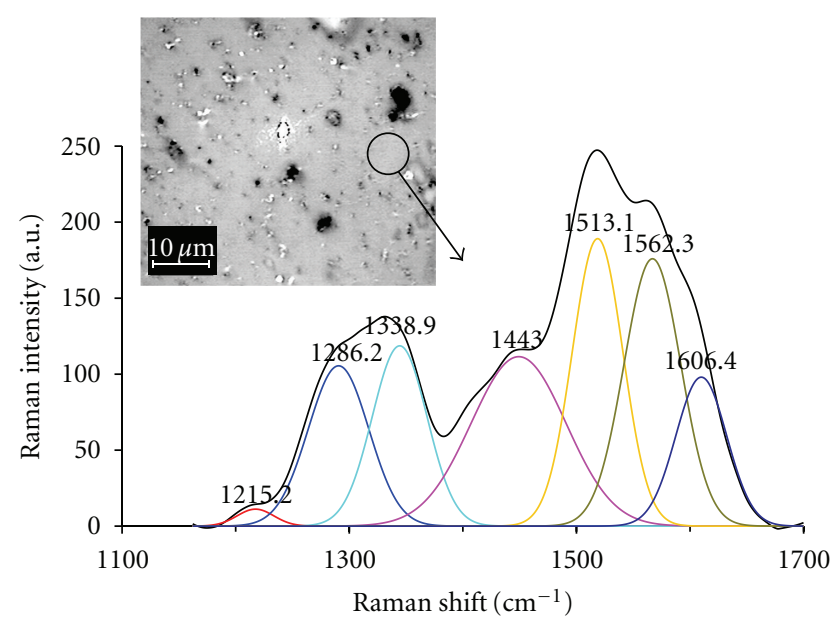

Figure 6: Deconvoluted Raman spectrum of C-Co (0.3\%) film into three D-G pairs of Gaussian components plus one supplementary peak.

originated from $\mathrm{E}_{2 \mathrm{~g}}$ symmetry of bond-stretching vibrations of $\mathrm{sp}^{2}$ carbon sites. Nanocrystalline graphite and amorphous carbon have an additional peak referred to as the $\mathrm{D}$ peak at around $1355 \mathrm{~cm}^{-1}$ and originated from the $A_{1 g}$ breathing vibrations of the sixfold carbon rings. The $\mathrm{D}$ mode is forbidden in an ideal graphite structure, but appears when the disorder increases. It has been reported that the intensity of the $\mathrm{D}$ mode varies inversely with grain size of the graphite [30]. The width of the $G$ and $D$ peaks is due to the bond disorder of the $\mathrm{sp}^{2}$ sites and the $\mathrm{G}$ peak is due to all $\mathrm{sp}^{2}$ sites, while the $\mathrm{D}$ peak is only due to the sixfold carbon rings [31]. The position of the $G$ peak moves to $1600 \mathrm{~cm}^{-1}$ when crystallized graphite change to nanocrystalline graphite and shift downwards to $1500 \mathrm{~cm}^{-1}$ for amorphous carbon when a loss of aromatic bonding appears [16]. A T peak due to $\mathrm{sp}^{3}$ vibrations at around $1060 \mathrm{~cm}^{-1}$ is obtained for UV excitation [32]. In general, an amorphous carbon film has a mixture of $\mathrm{sp}^{3}$ (diamond like) and $\mathrm{sp}^{2}$ (graphite like) bonds.

The microstructure of our films was characterized by a micro-Raman spectroscope. The laser beam was focused onto the sample surface using an optical microscope with a magnification of $50 \mathrm{x}$ (laser spot area of about $3 \mu \mathrm{m}^{2}$ ). On the surface of the films, some microparticles are visible under the optical microscope (Figure 5). The Raman spectra of the microparticles show two situations some spectra exhibit two bands at $1590 \mathrm{~cm}^{-1}$ and $1350 \mathrm{~cm}^{-1}$ which correspond, respectively, to the $G$ band originated from the $E_{2 g}$ bondstretching vibrations of $\mathrm{sp}^{2}$-bonded clusters and the $\mathrm{D}$ band from the $A_{1 g}$ breathing vibrations of the sixfold carbon rings (Figure $5(\mathrm{a})$ ); the position of the $\mathrm{G}$ band is close to that of nanocrystalline graphite of nanometer-sized clusters [16]. For some spectra, the $\mathrm{G}$ band is shifted to lower wavenumbers $\left(1470 \mathrm{~cm}^{-1}\right)$, suggesting that the $\mathrm{sp}^{2}$-bonded clusters are far from the sixfold carbon rings as it happens in fullerene or amorphous carbon [16] (Figure 5(b)). Let us discuss now the data obtained from the Raman investigation in regions of the surface without microparticles. Figure 6 shows Raman spectrum obtained for a $03 \%$-cobalt-doped carbon thin film.
This spectrum exhibits several overlapping bands in the range $1200-1650 \mathrm{~cm}^{-1}$. The broad band can be decomposed into subbands at 1215, 1286, 1339, 1443, 1513, 1562, and $1600 \mathrm{~cm}^{-1}$ (Figure 6). The peaks at 1562 and $1339 \mathrm{~cm}^{-1}$ are attributed to the D-G pair (D at $1339 \mathrm{~cm}^{-1}$ and $G$ at $1562 \mathrm{~cm}^{-1}$ ) belonging to nanocrystalline graphite clusters. The second D-G pair (D at $1286 \mathrm{~cm}^{-1}$ and $G$ at $1513 \mathrm{~cm}^{-1}$ ) can be assigned to clusters that have a bonding structure rather similar to that of amorphous carbon. The modes at 1215 and $1443 \mathrm{~cm}^{-1}$ can be attributed to Raman shift of $\mathrm{C}-\mathrm{C}$ and $\mathrm{C}=\mathrm{C}$ bonds observed in trans- and cis-polyacetylene chains [33]. Finally, the supplementary peak centered around $1600 \mathrm{~cm}^{-1}$ can be identified as a fullerene vibration mode $[34,35]$. Similar features associated with mixed structures have also been reported previously for other type of metal doped carbon films $\left(\mathrm{CN}_{\mathrm{X}}-\mathrm{Ni}\right)$ [36]. The analyse of the Raman spectra with increasing cobalt concentration can be performed in the framework of the phenomenological threestage model of Ferrari and Robertson [31]. In this model, an amorphization trajectory ranging from graphite to diamond is defined; the Raman spectra of all disordered carbons are classified within a three-stage model of increasing disorder as a function of the $G$ peak position and the relative integrated intensity ratio $\mathrm{I}_{\mathrm{D}} / \mathrm{I}_{\mathrm{G}}$ of the $\mathrm{D}$ and $\mathrm{G}$ peaks. In our samples, the relative integrated intensity ratio $I_{D} / I_{G}$ for the $D-G$ pair attributed to nano-crystalline graphite clusters goes from 0.47 for pure carbon sample to 1.47 for $2 \%$ cobalt sample, for the D-G pair attributed to amorphous carbon regions, the $\mathrm{I}_{\mathrm{D}} / \mathrm{I}_{\mathrm{G}}$ ratio goes from 0.31 to 0.66 according to the increasing cobalt content. Moreover, the integrated intensities of modes assigned to fullerene and polyacetylene chains tend to increase with the cobalt content of the films. These results suggest that the presence of cobalt in the films modifies the arrangement of the different phases of carbon in the films, increases the disorder of the graphite layer by decreasing the aromatic bonds to the detriment of polyacetylene chains, and favors the growth of fullerene structure.

\section{Conclusion}

The correlation between the microstructure by using HRTEM and vibrational properties by using infrared and Raman spectroscopies, of cobalt-carbon thin films obtained by pulsed anodic electric arc system, has allowed us to identify the nature of various bondings which coexist in this material. These films show a complex microstructure composed of amorphous and crystallized zones and cobalt aggregates. We have attempted to determine the evolution of the arrangement of the different phases of carbon as function of the cobalt content in these films.

\section{Acknowledgment}

The authors are grateful to A. Cantaluppi for technical help.

\section{References}

[1] P. Stamp, "Magnets get their act together," Nature, vol. 359, no. 6394, pp. 365-366, 1992. 
[2] B. Barbara, "Novel magnetic structures and nanostructures," Journal of Magnetism and Magnetic Materials, vol. 156, no. 13, pp. 123-127, 1996.

[3] T. Hayashi, S. Hirono, M. Tomita, and S. Umemura, "Magnetic thin films of cobalt nanocrystals encapsulated in graphite-like carbon," Nature, vol. 381, no. 6585, pp. 772-774, 1996.

[4] X. Han, F. Yan, A. Zhang et al., "Structure and tribological behavior of amorphous carbon films implanted with $\mathrm{Cr}+$ ions," Materials Science and Engineering A, vol. 348, no. 1-2, pp. 319-326, 2003.

[5] X. Nie, J. C. Jiang, L. D. Tung, L. Spinu, and E. I. Meletis, "Multifunctional Co-C nanocomposite thin films," Thin Solid Films, vol. 415, no. 1-2, pp. 211-218, 2002.

[6] V. V. Uglova, V. M. Anishchik, Y. Pauleau et al., "Relations between deposition conditions, microstructure and mechanical properties of amorphous carbon-metal films," Vacuum, vol. 70, no. 2-3, pp. 181-185, 2003.

[7] G. J. Kovacs, G. Safran, O. Geszti, T. Ujvari, I. Bertoti, and G. Radnoczi, "Structure and mechanical properties of carbonnickel and $\mathrm{CNx}$-nickel nanocomposite films," Surface and Coatings Technology, vol. 180-181, pp. 331-334, 2004.

[8] E. Liu, X. Shi, L. K. Cheah et al., "Electrical behaviour of metal/tetrahedral amorphous carbon/metal structure," SolidState Electronics, vol. 43, no. 2, pp. 427-434, 1999.

[9] J. C. Orlianges, C. Champeaux, A. Catherinot et al., "Electrical properties of pure and metal doped pulsed laser deposited carbon films," Thin Solid Films, vol. 453-454, pp. 291-295, 2004.

[10] T. Takeno, Y. Hoshi, H. Miki, and T. Takagi, "Activation energy in metal-containing DLC films with various metals of various concentrations," Diamond and Related Materials, vol. 17, no. 7-10, pp. 1669-1673, 2008.

[11] J. M. Bonard, S. Seraphin, J. E. Wegrowe, J. Jiao, and A. Chatelain, "Varying the size and magnetic properties of carbonencapsulated cobalt particles," Chemical Physics Letters, vol. 343, no. 3-4, pp. 251-257, 2001.

[12] W. B. Mi, L. Guo, E. Y. Jiang, Z. Q. Li, P. Wu, and H. L. Bai, "Structure and magnetic properties of facing-target sputtered Co-C granular films," Journal of Physics D, vol. 36, no. 19, pp. 2393-2399, 2003.

[13] V. Zhukova, J. M. Blanco, A. Zhukov, J. Gonzalez, A. Torcunov, and V. Larin, "Magnetostriction of glass-coated Co-rich amorphous microwires and its dependence on current annealing," Journal of Magnetism and Magnetic Materials, vol. 254-255, pp. 94-96, 2003.

[14] H. Wang, M. F. Chiah, W. Y. Cheung, and S. P. Wong, "Structure, magnetic and electrical properties of soft magnetic $\mathrm{Co}-$ C amorphous thin films," Physics Letters A, vol. 316, no. 1-2, pp. 122-125, 2003.

[15] N. Nishi, K. Kosugi, K. Hino, T. Yokoyama, and E. Okunishi, "Formation and magnetic characteristics of cobalt-carbon nanocluster magnets embedded in amorphous carbon matrices," Chemical Physics Letters, vol. 369, no. 1-2, pp. 198-203, 2003.

[16] J. Robertson, "Diamond-like amorphous carbon," Materials Science and Engineering R, vol. 37, pp. 129-281, 2002.

[17] D. H. C. Chua, W. I. Milne, B. K. Tay, P. Zhang, and X. Z. Ding, "Microstructural and surface properties of cobalt containing amorphous carbon thin film deposited by a filtered cathodic vacuum arc," Journal of Vacuum Science and Technology A, vol. 21, no. 2, pp. 353-358, 2003.

[18] R. K. Y. Fu, Y. F. Mei, L. R. Shen et al., "Molybdenum-carbon film fabricated using metal cathodic arc and acetylene dual plasma deposition," Surface and Coatings Technology, vol. 186, no. 1-2, pp. 112-117, 2004.

[19] N. Benchikh, F. Garrelie, K. Wolski et al., "Nanocomposite tantalum-carbon-based films deposited by femtosecond pulsed laser ablation," Thin Solid Films, vol. 494, no. 1-2, pp. 98-104, 2006.

[20] P. Dubcek, N. Radic, and O. Milat, "Characterization of grains in tungsten-carbon films Ul," Nuclear Instruments and Methods in Physics Research Section B, vol. 200, pp. 329-332, 2003.

[21] A. Anders, "Metal plasmas for the fabrication of nanostructures," Journal of Physics D, vol. 40, no. 8, Article ID 2272, 2007.

[22] P. J. Martin and A. Bendavid, "Review of the filtered vacuum arc process and materials deposition," Thin Solid Films, vol. 394, no. 1-2, pp. 1-15, 2001.

[23] L. Kumari, S. V. Subramanyam, S. Eto, K. Takai, and T. Enoki, "Metal-insulator transition in iodinated amorphous conducting carbon films," Carbon, vol. 42, no. 11, pp. 2133-2137, 2004.

[24] L. Kumari and S. V. Subramanyam, "Tuning of the metalinsulator transition in iodine incorporated amorphous carbon," Journal of Applied Physics, vol. 99, no. 9, Article ID 096107, 2006.

[25] E. Bustarret, P. Achatz, B. Sacépé et al., "Metal-to-insulator transition and superconductivity in boron-doped diamond," Philosophical Transactions of the Royal Society A, vol. 366, no. 1863, pp. 267-279, 2008.

[26] A. Tembre, M. Clin, J.-C. Picot et al., "Magnetic and electric properties of C-Co thin films prepared by vaccum arc technique," Journal of Alloys and Compounds, vol. 509, no. 37, pp. 9123-9126, 2011.

[27] S. A. Bates, J. A. Rhodes, C. M. L. Rittby, and W. R. M. Graham, "Fourier transform infrared observation of the $v_{1}(\sigma)$ mode of linear $\mathrm{CoC}_{3}$ trapped in solid Ar," Journal of Chemical Physics, vol. 127, no. 6, Article ID 064506, 6 pages, 2007.

[28] B. Dischler, A. Bubenzer, and P. Koidl, "Bonding in hydrogenated hard carbon studied by optical spectroscopy," Solid State Communications, vol. 48, no. 2, pp. 105-108, 1983.

[29] G. M. Matenoglou, H. Zoubos, A. Lotsari et al., "Metal-containing amorphous carbon (a-C:Ag) and AlN (AlN:Ag) metallo-dielectric nanocomposites," Thin Solid Films, vol. 518, no. 5, pp. 1508-1511, 2009.

[30] F. Tuinstra and J. L. Koening, "Raman spectrum of graphite," Journal of Chemical Physics, vol. 53, no. 3, pp. 1126-1130, 1970.

[31] A. C. Ferrari and J. Robertson, "Interpretation of Raman spectra of disordered and amorphous carbon," Physical Review B, vol. 61, no. 20, pp. 14095-14107, 2000.

[32] A. C. Ferrari and J. Robertson, "Resonant Raman spectroscopy of disordered, amorphous, and diamondlike carbon," Physical Review B, vol. 64, no. 7, Article ID 075414, 13 pages, 2001.

[33] S. Shibahara, M. Yamane, K. Ishikawa, and H. Takezoe, "Direct synthesis of oriented trans-polyacetylene films," Macromolecules, vol. 31, no. 11, pp. 3756-3758, 1998.

[34] V. Paillard, "On the origin of the $1100 \mathrm{~cm}^{-1}$ Raman band in amorphous and nanocrystalline $\mathrm{sp}^{3}$ carbon," Europhysics Letters, vol. 54, no. 2, pp. 194-198, 2001.

[35] V. Vincenzo, M. Pagliai, and G. Cardini, "The infrared and Raman spectra of fullerene C70. DFT calculations and 
correlation with C60," Journal of Physical Chemistry A, vol. 106, no. 9, pp. 1815-1823, 2002.

[36] G. J. Kovacs, M. Veres, M. Koos, and G. Radnoczi, "Raman spectroscopic study of magnetron sputtered carbon-nickel and carbon nitride-nickel composite films: the effect of nickel on the atomic structure of the C/CNx matrix," Thin Solid Films, vol. 516, no. 21, pp. 7910-7915, 2008. 


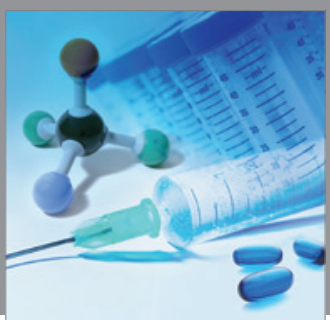

International Journal of

Medicinal Chemistry

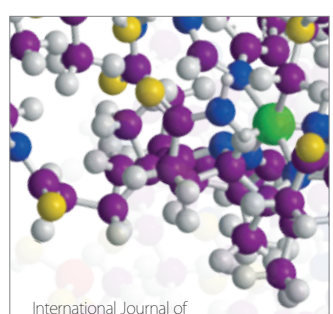

Carbohydrate Chemistry

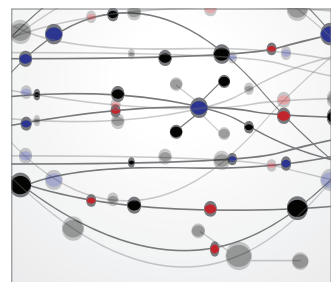

The Scientific World Journal
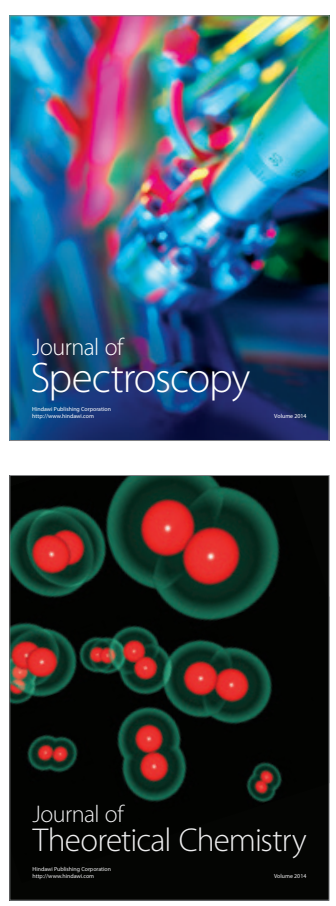
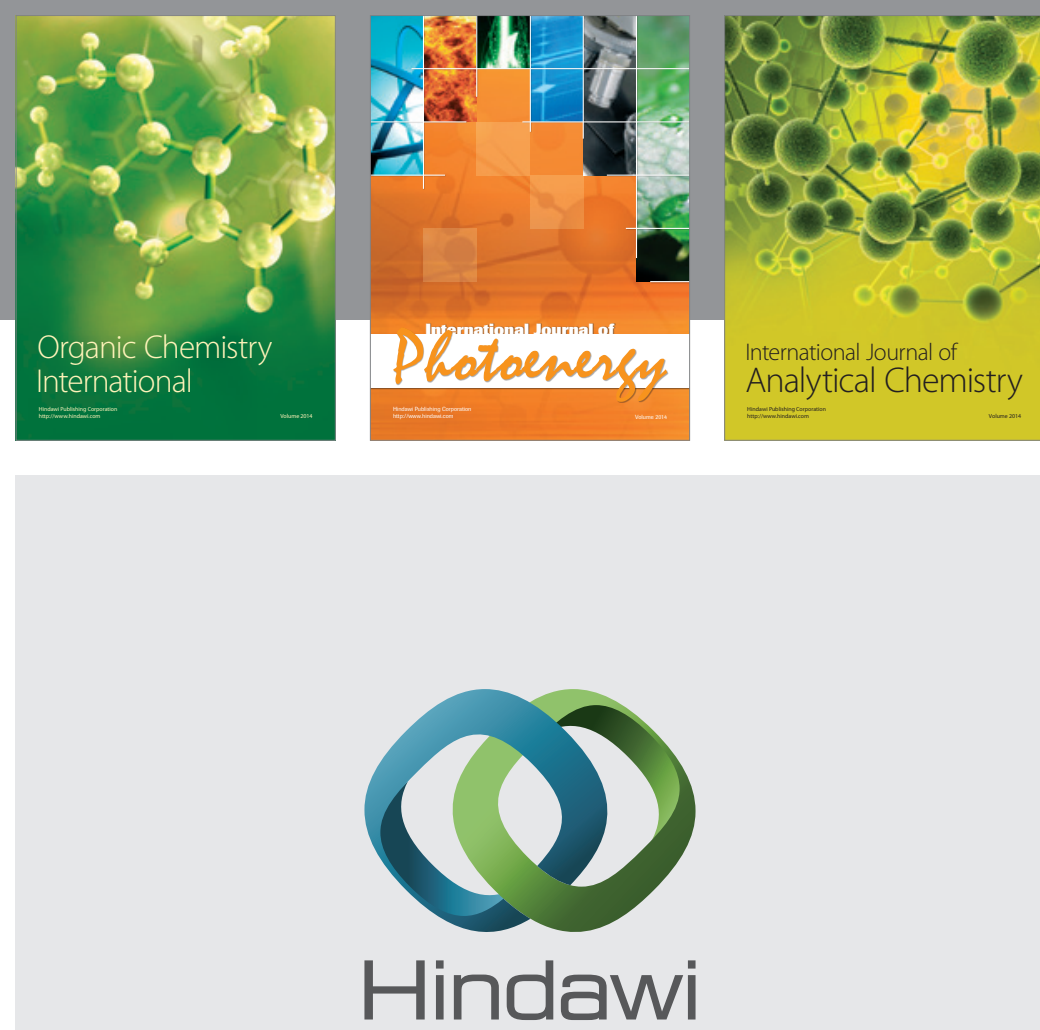

Submit your manuscripts at

http://www.hindawi.com
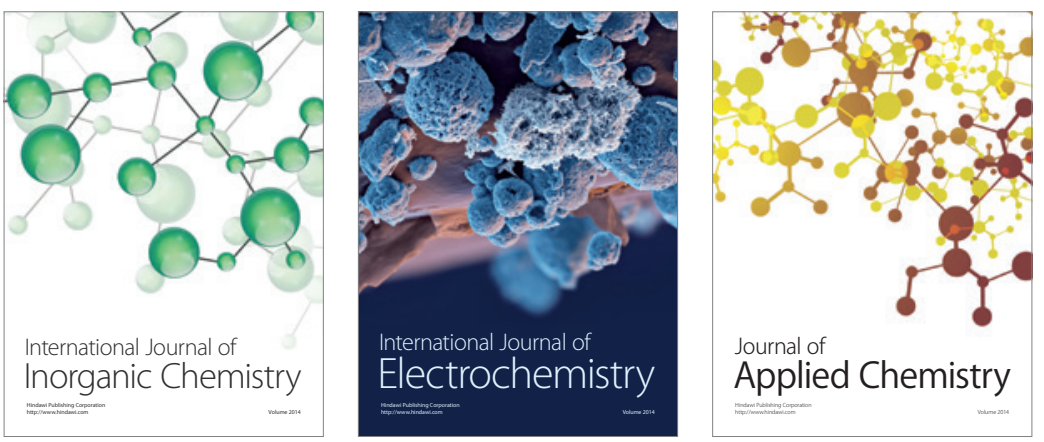

Journal of

Applied Chemistry
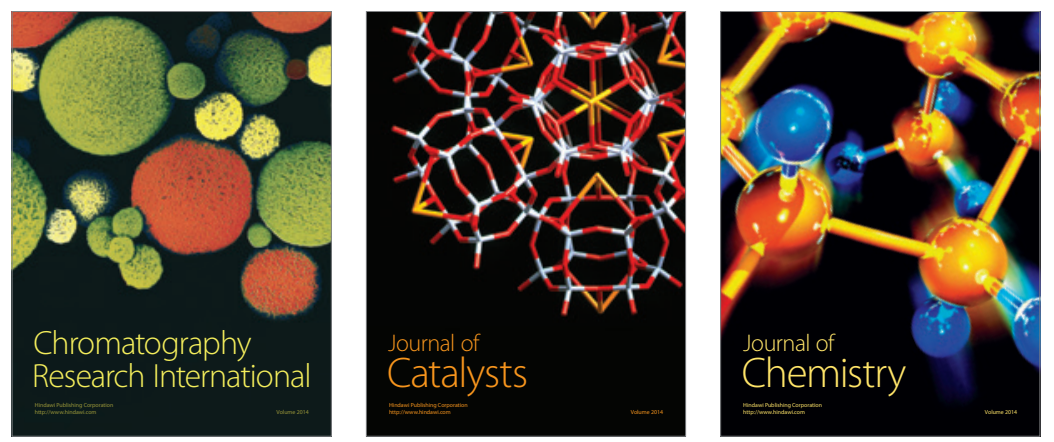
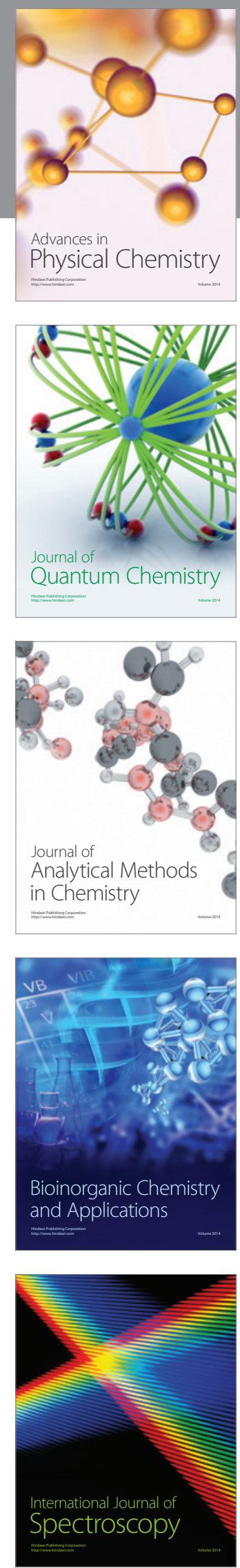